\title{
Psychological Stress as an Impact of Dysfunction on Physical Health
}

Dr George Varvatsoulias

Chartered Psychologist, Cognitive-Behavioural Therapy Practitioner

Corresponding Author: Dr George Varvatsoulias, Barnet IAPT, NHS England. E-mail: George.Varvatsoulias@ outlook.com

Received Date: January 03, 2020; Accepted Date: January 28, 2020; Published Date; January $29,2020$.

Citation: George Varvatsoulias, Psychological Stress as an Impact of Dysfunction on Physical Health, J. Psychology and Mental Health Care. Doi: $10.31579 / 2637-8892 / 071$

Copyright: (C) 2020 George Varvatsoulias. This is an open-access article distributed under the terms of the Creative Commons Attribution License, which permits unrestricted use, distribution, and reproduction in any medium, provided the original author and source are credited.

\section{Abstract}

The aspect of stress influences physical health. In this paper will be examined the impact of psychological stress on general health. There was conducted a study with correlational design, measuring the levels of stress and health. Participants were given a Perceived Stress Questionnaire to answer, whereas a Health Scale to rate. Both scores were collected and collated, and a significant negative correlation was drawn supporting the prediction of the increase of stress and the decrease of health. It was suggested that by using a wider range of measures, as well as a greater sample of participants, the results could be more objective and accurate on both the rates of stress and health.

Keywords: Stress; physical health; correlational design

\section{Introduction}

Stress is a threat. This consideration comes from Cannon (1932), who was the first to interpret stress as something which leads oneself towards either fighting or escaping from a perceived danger. He claims that stress takes place in man after a perceived threat that motivates the man's sympathetic and hormonal system to fight back or flee from a danger. Stress is a physiological response for Cannon.

Selye (1956) developed Cannon's aspect about fighting or escaping from the stress impact, by explaining the implication of 'perceived threat' as a tool towards understanding the concept of stress deeper. Humans feel embarrassed from experiences of everyday living related to inflictions of heat and cold and infections that lead to illnesses. Such experiences influence the human physiological functioning and result to consequences of physiological changes. He developed a three stages scale, which is known as the General Adaptation Syndrome, claiming the physiological response of man before stress

1. Alarm: Via a threat the body is mobilized and activated to face and counter-attack the experience of stress. The sympathetic and hormonal system is considered to be the means towards facing threat.

2. Resistance: The threat is confronted via physiological changes which attempt to fight back or escape from it.

3. Exhaustion: After the body gets alarmed or resists to the experience of threat, the organism is getting exhausted from all that effort. Thus, stress starts to affect the body and develop illnesses. Although, there is no precise evidence how illnesses can be influenced by stress, a person found under physiological pressure, experiences it with considerable tension which affects his health system Such as have been investigated coronary heart diseases, gastrointestinal disorders, sleep disorders and so on.

Cohen et al. $(1983,1991)$ conducted two studies where they investigated the impact of stress to people who had been subjected to the common cold. In the first experiment (1983) they questioned whether exposure to respiratory viruses suppresses psychological stress.
Participants were given nasal drops contained one of five respiratory viruses and concluded that psychological stress is associated with infectious illness. In the second experiment (1991) they subjected participants to the common cold, influenza or cold viruses, and examined stress in relation to the magnitude of infection and its susceptibility to the immune system. They concluded that life events demonstrate a serious impact to psychological stress and vice versa.

Glaser et al. (1987) conducted an experiment to examine the health implications of stress on immune system. Their participants were medical students who were measured through three periods of their academic life. They concluded that they were more susceptible to infectious illnesses during exam periods.

Segerstrom et al. (2004) conducted also an experiment investigating the implications of psychological stress on the immune system. They have collected data, based on effect sizes of a metaanalysis derived from 293 independent studies; they have discussed the various areas of appearance of psychological stress by over-viewing the immune system. They collated them and concluded that, parameters of the fight-or-flight situations faced by the individuals, elicit detrimental changes in the immune system. The more an individual operates in life under psychological stress, the more the components of the immune system are affected in a potentially damaging way.

The rationale for this research is that stress and health are associated one another. It is therefore predicted that the higher the levels of stress the poorer the levels of health. As one variable increases the other decreases, indicating a negative correlation.

\section{Method}

\section{Design}

The design will be correlational and the variables will refer to the perceived level of stress and the perceived measure of health.

\section{Participants}


The participants recruited were a convenient sample from undergraduate UEL psychology students. They were four males and thirteen females. Their mean age was 22.5 and the standard deviation 6.8 .

\section{Materials}

\section{Procedure}

The experiment conducted at the Psychology Lab of the University of East London. After admission, participants were thanked for coming, they were given a pen and were told to sit. The order of the events was to complete the Perceived Stress Scale first and then, the Perceived Health Status.

In the Perceived Stress Scale Questionnaire they were asked about their feelings and thoughts during the last month. The questions referred to how participants have felt a certain way. By thinking of the most reasonable estimate participants were asked to answer the questionnaire quickly. They were also asked to score their answer in relation to the following ratings: $0=$ never, $1=$ almost never, $2=$ sometimes, $3=$ fairly often, $4=$ very often. They were advised to avoid zero rating and try to be as much as accurate they could.
The Perceived Stress Scale Questionnaire (Appendix 1) by Cohen et al. (1983) and the Perceived Health Status Visual Analogue Scale (Appendix 2) by Weinman et al. (1995). The questionnaire was an A4 page containing 14 questions to be answered. The Visual Analogue Scale was also an A4 page and had a 'poor-to-perfect' line to be rated

For the Perceived Health Visual Analogue Scale, participants were asked to rate their cur- rent state of health by placing a cross where on the line they thought it corresponded better.

Finally, participants were thanked again and were informed that the data collected from both events will remain anonymous.

\section{Results}

\section{Descriptive Statistics}

Each question was given a score for stress and health. There was employed a reverse rating, in order for the data to be defined. After completion, the raw data were collated on a stress and health scoring sheet and were put in the SPSS.

\begin{tabular}{|l|l|l|}
\hline Mean & Standard & Deviation \\
\hline Age & 22.5 & 6.8 \\
\hline Gender & 1.24 & .437 \\
\hline
\end{tabular}

\section{(Descriptives 1)}

Age: $n=17, M=22.5, S D=6.8$

Gender: $n=17, M=1.24, S D=.437$ (where 1 was designated for females and 2 for males) 


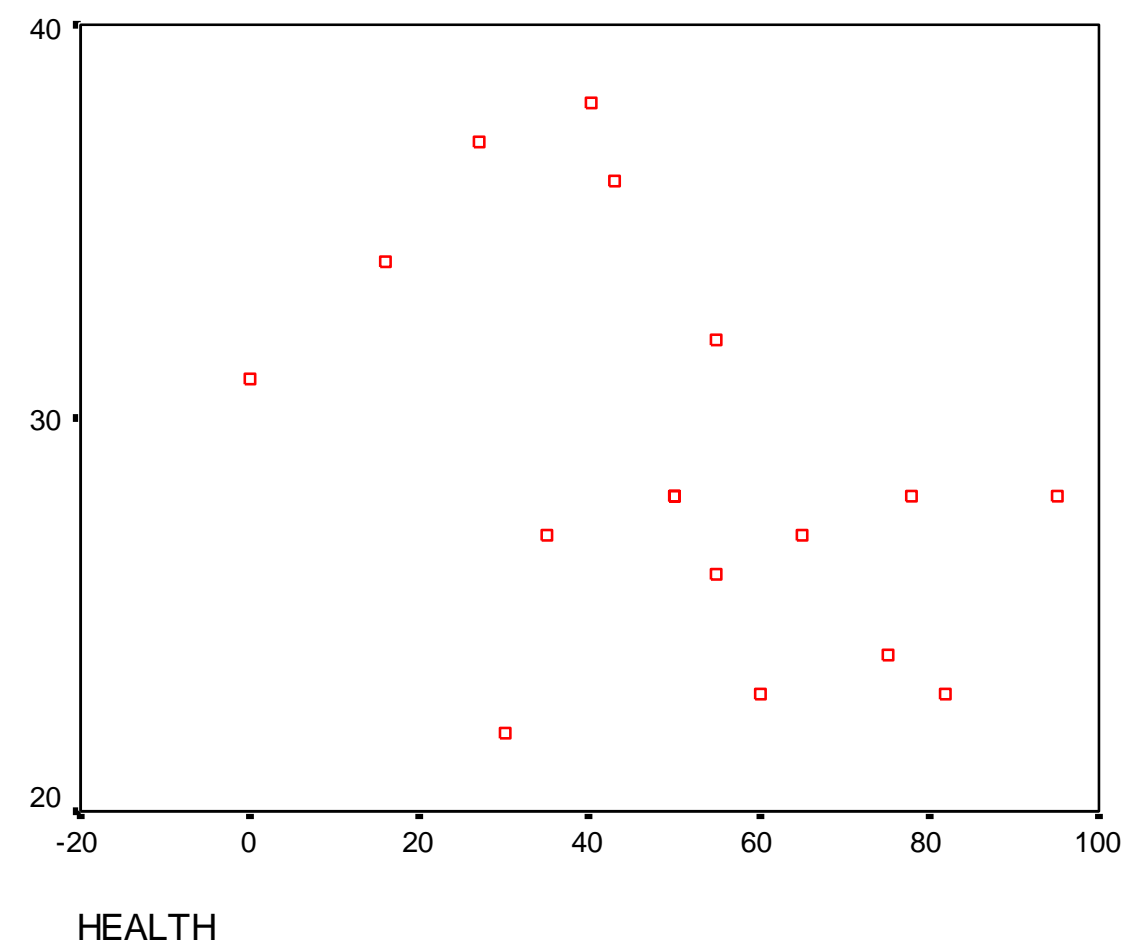

(Descriptives 2)

The scatter plot on health and stress presents the perceived stress and health level. Stress and Health scores are counted by millimetres. The scatter plot indicates a negative correlation between stress and health. In relation to the predicted outcome, the scatter plot shows that an increase of stress results to a decrease of health.

\section{Inferential Statistics}

\begin{tabular}{|l|l|l|}
\hline & Health & stress \\
\hline Pearson's correlation & 1 & -.457 \\
\hline Sig. (1-tailed) & .033 & \\
\hline
\end{tabular}

$\mathrm{r}=-.457, \mathrm{p}=.033, \mathrm{r}^{2}=-.457^{2}=.21$

The correlation coefficient is -.457 (-.46 by rounding it up), the (p) significance is .033 and the shared variance between perceived stress and perceived health is .21. The correlation coefficient is moderate (it is between 4 and 6) and negative, that means suitable and significant. The study is one-tailed; this is understood via the p-value $(.033<0.05)$, implying that once the stress is increased, health is decreased. The result supports the hypothesis tested.

\section{Discussion}

The findings support the hypothesis. There is a moderate negative correlation between scores of stress and scores of health, meaning that the more stressful an individual is, the less he scores well on health. The association between stress and health is one-tailed, implying the decrease of health, once the psychological stress is increased. Rounding up the correlation coefficient there is an amount of -.46 , whilst squaring it the shared variance is .21 . The correlation is significant because the $\mathrm{p}$-value is less than $0.05(.033)$.

The impact of stress is validly considered to affect the health state of an individual. People under stress not only react inconsistently but also precariously. Studies have concluded that the overall state of health can be irretrievably affected by stress. It is generally believed 
(Carlson et al., 2004) that psychological stress is related to a person's lifestyle. If the lifestyle is healthy it enhances the person's physical state along with his psychological well-being. If it is unhealthy it decreases the psychosomatic balance of the self. Stress is therefore an endangered experience within a person's life. Up today it is maintained that psychological stress generally causes or leads towards chronic heart diseases (CHD), cancer, stroke, lung diseases, not to mention the susceptibility to the common cold, upon which many studies have been based.

In the experiment conducted, it was easy to be found how the state of stress influences the psychological life of an individual. According to the results, there is a negative association between stress and health. Since the first is enhanced the second is lessened. The prediction has been supported and the correlation between stress and health is a moderate one. However, there are other aspects as well, in order stress and health to be further discussed. By reiterating the experiment to the population at large this may result to a larger increase/decrease on both of the perceived variables. A small sample of participants cannot predict how a wider population will react, although the results drawn support the hypothesis investigated. If the sample was to be as large as the community of people of a certain neighbourhood, results could be more relative, regarding a clearer understanding of the association between stress and health.

Alongside with the small sample, female participants were more than their male counterparts. By having a number of only four males and thirteen females it means that the sample was indicative. Genders have a different understanding and interpretation on stress. Blanchard et al. (1993) claim that, males tend to be actually involved, when coping with stress, whilst also retreat, when feeling defeated by it. Females, on the other hand, demonstrate a more emotional involvement. They help others more and this is considered as a means towards overcoming stress. Differences between genders should denote a compilation of a different questionnaire for both, in order the ratings to reflect the gender differences on certain occasions and dealings with life.

To compile a questionnaire there would be worth to be included some other psychological factors too. According to Linsky et al. (1995), psychological factors relating to stress refer to the mood of participant, his self-esteem, his cognitive understanding about himself, his way of perceiving others, as well as his experiences in life. Questions to be comprised could be: Does he think that others exploit him? Does he feel abandoned in life? Does he behave in a way which is inappropriate to the given cultural status? Such questions express an understanding about psychological stress, not only in universal forms, but in social and cultural too.

To have a convenient sample with undergraduate psychology students, it is also indicative. The main reason is it was part of a preparation for a longitudinal study about physical health and elements of anxiety among students during their first year of studying psychology. Ader (2001) posits that an experiment on correlations associated with age, gender, samples of people, various aspects of influencing experiences in life, it is better to be studied in the population at large, so the results to have a more overlapping understanding, along with a constructive application to the real world.

The age of the participants varies as well, 18 to 21,26 to 30 and 30 to 41. There are some gaps in-between which need to be considered, if the experiment was to be reiterated. In other words, participants of a more average age could exhibit better and more accurate results, because of their similar lifestyle, aspirations and expectations.

If the same experiment was to be retrieved, a good indication about stress and health could be the data to be collected in three ways: in the morning, coming back home after a busy day and returning from holidays or to take place in two different seasons: winter and summer. Furthermore, the biological basis of stress could also be a perspective worth to be investigated (Selye, 1976). Participants could be asked to wear a wristwatch receiver during their daily activities, in order their heartbeat and pulse to be measured. Or, at times of acute tense, measures of sugar blood could also be assessed.

People under stress demonstrate low levels on general health. Stress is a procedure which piles up negative effects in a man's life. The direction of the association between stress and health is significantly negative. The interpretation of stress lies somewhere in-between the needs of a person and his whereabouts in life. Positive thinking and a balanced sequence of the events in life assist the individual towards coming to terms with the disadvantages of psychological stress (П $\alpha \pi \alpha \delta$ ó $о 0 v-\lambda \circ \varsigma, 1994)$. People by manifesting less stress reflect to a better health, regarding their experiences and how to cope with them.

\section{References}

1. Ader, P. (2001): Psychoneuroimmunology. Current Direction in Psychological Science, 10, pp. 94-98.

2. Blanchard, D. C., Sakai, R. R., McEwen, B., Weiss, S. M., and Blanchard, R. J. (1993): Subordination stress: Behavioural, brain and neuroendocrine correlates. Behavioural Brain Research, 58, pp. 113-121.

3. Cannon, Walton (1932): Cited in Elizabeth Attree's (2005) PY1001/2 Research Methods Semester B Booklet.

4. Carlson, Neil R., Martin, Neil G., Buskist, William (2004): Psychology. Second European Edition. Harlow Essex: Pearson Education Limited.

5. Cohen, S., Kamarck, T., Mermelstein, R. (1983): A global measure of perceived stress. Journal of Health and Social Behaviour, 24, pp. 385-396.

6. Cohen, S., Tyrell, D. A. J., Smith, A. P. (1991): Psychological stress and susceptibility to the common cold. New England Journal of Medicine, 359 (9), pp. 606-612.

7. Glasser, R., Rice, J., Sheridan, J., Fertal, R. (1987): Stressrelated immune suppression: Health Implications. Brain, Behaviour and Immunity, 1 (1), pp. 7-20.

8. Linsky, A. S., Bachman, R., Straus, M. A. (1995): Stress, Culture and Aggression. New Haven CT: Yale University Press.

9. Papadopoulos, Nikos G. (1994): Dictionary of Psychology with Quadruple Time. Athena.

10. Segerstrom, Suzanne C., Miller, Gregory E. (2004): Psychological Stress and the Human Immune System: A Metaanalytic Study of 30 years of Inquiry. Psychological Bulletin 130 (4), pp. 601-630.

11. Selye, Hans (1956): The Stress of Life. New York: McGrawHill.

12. (1976): Stress without Distress. New York: Harper \& Row.

13. Weinman, Wright \& Johnston (1995): Health Status and HealthRelated Quality of Life Measures in Health Psychology: A User's Portfolio. NFER-Nelson. 


\section{Appendix 1}

\section{PERCEIVED STRESS SCALE}

Name:

Date:

Record Number:

\section{Instructions}

The questions in this scale ask you about your feelings and thoughts during the last month. In each case, you will be asked to indicate how often you felt or thought a certain way. Although some of the questions are similar, there are differences between them and you should treat each one as a separate question. The best approach is to answer each question fairly quickly. That is, don't try to count up the number of times you felt a particular way, but rather indicate the alternative that seems like a reasonable estimate.

For each question choose from the following alternatives:

$0=$ never

$1=$ almost never

2 = sometimes

3 = fairly often

4 = very often

1. In the last month, how often have you been upset because of something that happened unexpectedly?

2. In the last month, how often have you felt that you were unable to control the important things in your life?

3. In the last month, how often have you felt nervous and stressed?

4. In the last month, how often have you dealt with irritating life hassles?

5. In the last month, how often have you felt that you were effectively coping with important changes that were occurring in your life?

6. In the last month, how often have you felt confident about your ability to handle your personal problems?

7. In the last month, how often have you felt that things were going your way?

8. In the last month, how often have you found that you could not cope with all the things you had to do?

9. In the last month, how often have you been able to control irritations in your life?

10. In the last month, how often have you felt that you were on top of things?

11. In the last month, how often have you been angered because of things that happened that were outside of your control?

12. In the last month, how often have you found yourself thinking about things that you have to accomplish?

13. In the last month, how often have you been able to control the way you spend your time?

14. In the last month, how often have you felt difficulties were piling up so high that you could not overcome them?

(c) American Sociological Association, 1983. From 'A global measure of perceived stress,' Journal of Health and Social Behavior, 24, 385-96. Reproduced with the kind permission of the author, Sheldon Cohen, and the publishers.

This measure is part of Measures in Health Psychology: A User's Portfolio, written and compiled by Professor Marie Johnston, Dr Stephen Wright and Professor John Weinman. Once the invoice has been paid, it may be photocopied for use within the purchasing institution only. Published by The NFER-NELSON Publishing Company Ltd, Darville
House, 2 Oxford Road East. Windsor, Berkshire SL4 1DF, UK. 


\section{Perceived Health Status Visual Analogue Scale}

Please rate your current state of health by placing a cross on the line which you feel best corresponds to this

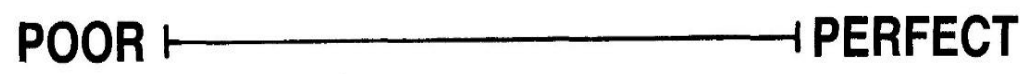

Weinman, Wright \& Johnston (1995): Health Status and Health-Related Quality of Life Measures in Health Psychology: A User's Portfolio. NFER-Nelson. 
(c) $($ )

This work is licensed under Creative

Commons Attribution 4.0 License

To Submit Your Article Click Here: Submit Manuscript

DOI: $10.31579 / 2637-8892 / 071$
Ready to submit your research? Choose Auctores and benefit from:

* fast, convenient online submission

* rigorous peer review by experienced research in your field

* rapid publication on acceptance

* authors retain copyrights

* unique DOI for all articles

* immediate, unrestricted online access

At Auctores, research is always in progress.

Learn more www.auctoresonline.org/journals/psychology-and-mentalhealth-care 